\title{
Added Value of SPECT-CT Imaging in the Diagnosis of Unilateral Active Mandibular Hypercondylia in Adult: A Case Report and Review
}

\author{
F. Fokoue*, S. El Mselmi, N. Abaouz, N. Ismaili Alaoui \\ Faculty of Medicine and pharmacy, University Sidi Ben Abdellah, Fez, Morocco \\ Email: ^fabricefokoue2017@gmail.com
}

How to cite this paper: Fokoue, F., E Mselmi, S., Abaouz, N. and Ismaili Alaoui, N. (2020) Added Value of SPECT-CT Imaging in the Diagnosis of Unilateral Active Mandibular Hypercondylia in Adult: A Case Report and Review. Advances in Molecular Imaging, 10, 1-5.

https://doi.org/10.4236/ami.2020.101001

Received: January 12, 2020

Accepted: January 26, 2020

Published: January 29, 2020

Copyright $\odot 2020$ by author(s) and Scientific Research Publishing Inc. This work is licensed under the Creative Commons Attribution International License (CC BY 4.0).

http://creativecommons.org/licenses/by/4.0/

\begin{abstract}
Planar bone Scintigraphy has been frequently used to assess the active or inactive nature of mandibular hypercondylia. We report here the case of a patient whose diagnosis of active mandibular hypercondylia was retained after a complement with SPECT/CT imaging, the planar bone scan being negative. This case confirms the use of SPECT/ CT as the examination of choice for full assessment of mandibular hypercondylia in adults. Using bone Scintigraphy SPECT/CT improves both sensitivity and specificity of diagnosing this condition.
\end{abstract}

\section{Keywords}

Hypercondylia, Mandibular Condylar Hyperplasia, Bone Scan, SPECT CT

\section{Introduction}

Mandibular hypercondylia is a rare and autonomous bone disease due to the excessive growth of the condylar cartilage induced seemingly by a disruption of the feedback loops between the different histological layers leading to a persistence of the multiplication of prechondroblastic cells. Mandibular hypercondylia affects the overall development of the mandible and this condition is characterized clinically by atypical facial asymmetry, with a pronounced mandible anatomy, a disturbed occlusion, and a tilted occlusal plane [1]. Planar bone scintigraphy has been frequently used to assess the active or inactive nature of this situation [2] [3]. 


\section{Patient and Method}

The patient is a 43-year-old female, with no significant pathological history, who has had mandibular asymmetry for 10 years. She is directed to the nuclear medicine department for a scintigraphic evaluation of condylar activity following the diagnosis of left mandibular hypercondylia, which was revealed after completing dental panoramic examination supplemented by a craniofacial diagnostic CT scan.

Bone scintigraphy was completed in two stages: Acquisition of early images, followed by late static images focusing on the skull along with the anterior and posterior face. A tomoscintigraphy scan then focused on the skull and was coupled with a low dose CT scan (SPECT/CT) between 0 - 10 min, then 2 hours after IV injection of $740 \mathrm{MBq}(20 \mathrm{mCi})$ of metastable Technetium 99-labeled Methylene Diphosphonate (MDP-99mTC).

The acquisition of images was performed with a Siemens gamma camera model Symbia T6 2010. The analysis was done using a visual and quantitative approach. A relative bone fixation of 55\% (or more) was considered pathological.

\section{Results}

The planar bone scintigraphy did not show any asymmetry with radio tracer uptake in the early times (vascular and tissue), nor any abnormality in bone fixation in the late stage between the two mandibular condyles (Figure 1).

The complement by SPECT CT revealed an asymmetry of visual and quantitative fixation depending on the left mandibular condyle with an enlargement of left condyle in transversal, coronal and sagittal reconstruction images respectively thus allowing to conclude to an active left unilateral mandibular hypercondylia (Figure 2).

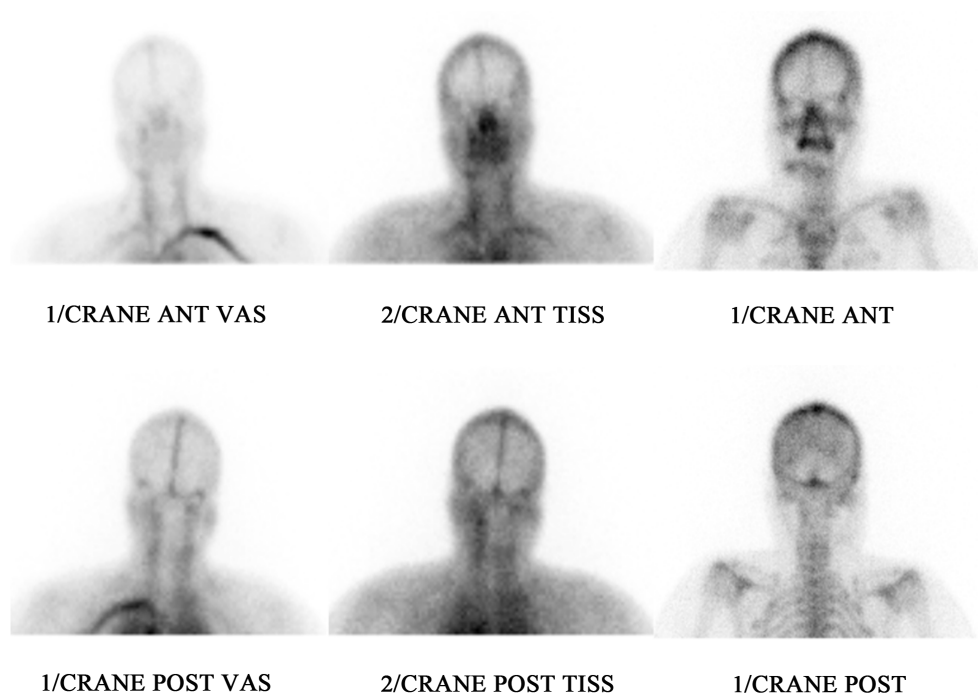

Figure 1. Planar bone scan: Static images focused on the skull performed between 0 - 10 $\mathrm{min}$, then 2 hours after IV injection of $740 \mathrm{MBq}(20 \mathrm{mCi})$ of MDP-Technetium $99 \mathrm{~m}$. 


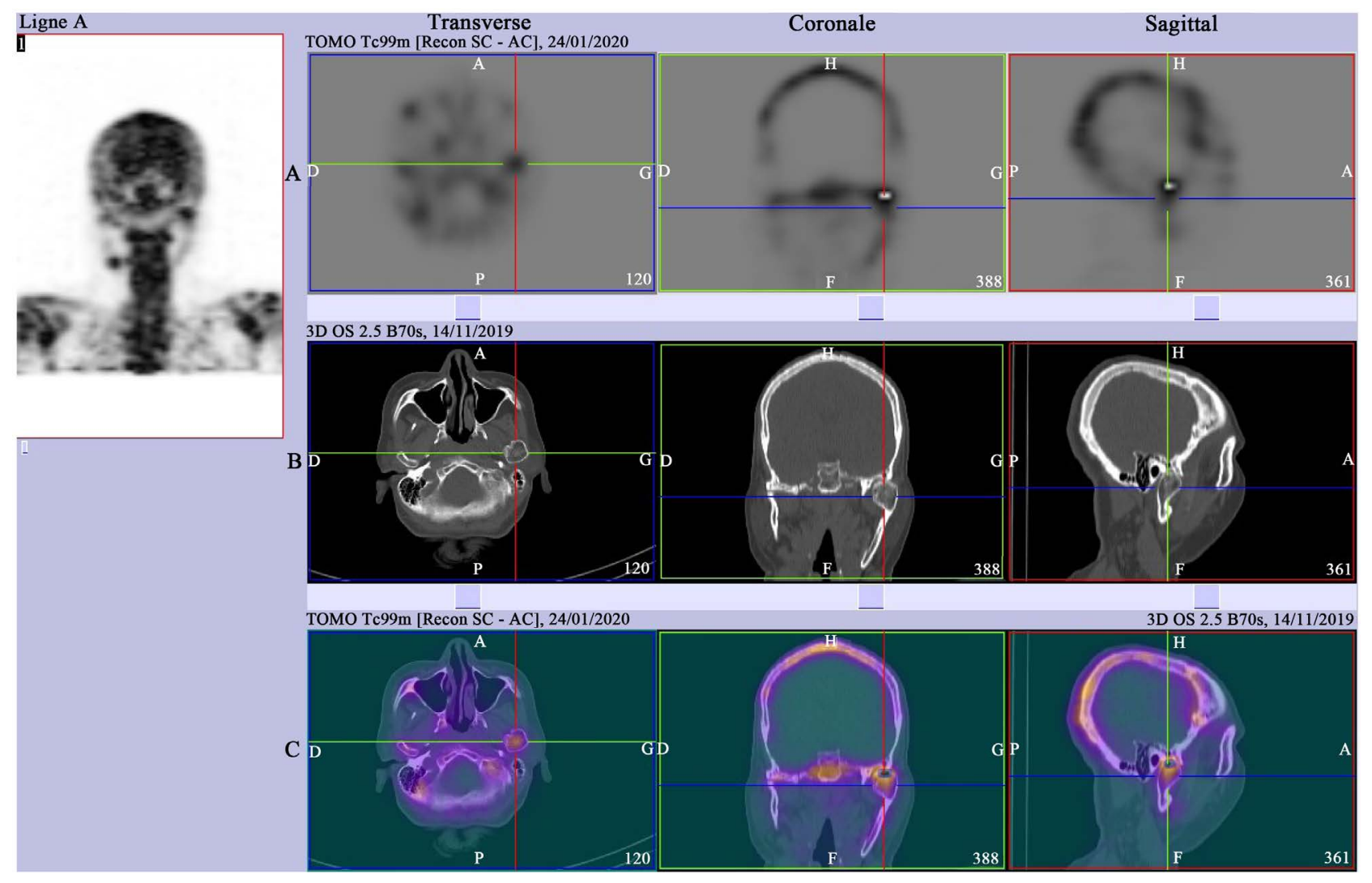

Figure 2. SPECT CT focused on the pathological area. The complement by SPECT CT revealed an asymmetry of visual and quantitative fixation depending on the left mandibular condyle with an enlargement of left condyle.

\section{Discussion}

Mandibular hypercondylia was first described by Robert Adams in 1836, while describing a case of rheumatoid arthritis [4]. It is a disease of the temporal-mandibular joint resulting in excessive mandibular growth, most often unilateral. It affects the overall development of the mandible and results clinically in an unsightly and functional problem.

Mandibular hypercondylia usually occurs between 10 and 30 years, with a female-dominated sex ratio of $69.6 \%$ according to Vernex-Boukerma. Cases between the ages of 9 and 80 have been reported in the literature, and this discrepancy could be explained by delays in diagnosis [1] [4].

The exact pathophysiology of mandibular hypercondylia is unknown, but several etiological factors have been reported, including hyper remodelling of post traumatic mandibular condyle, joint infection, hormonal disorders, and hypervascularization of the mandibular condyle, intrauterine changes and genetic factors [5].

Although the diagnosis can be formally established on histopathological exam, the radiological assessment following clinical examination remains essential to the diagnostic orientation. Information provided from a dental panorama and teleradiographic assessment, or diagnostic CT scan mostly allow the diagnosis of mandibular hypercondylia to be established. 
The place of bone scintigraphy has a different interest from other imaging methods because it allows assessing the osteoblastic activity of the condylar cartilage [2] [3]. In a context of clinical and radiological diagnosis of hypercondylia, a positive bone scan shows the active nature of the disease and allows therapy to be adapted.

The molecular imaging techniques commonly used are planar bone scintigraphy and single photon emission computered tomography (SPECT) which can be analysed quantitatively and qualitatively [5].

For most authors, SPECT can guide surgical management [6] and for others SPECT/CT could be used to measure residual activity after a condylectomy [7]. Condylectomy consists of a surgical excision of the cartilaginous cap, seat of the prechondroblastic cells, resulting in a definitive cessation of the pathological process. It is a key stage in the management of active hypercondylia [8].

In our study, all the modalities of bone scintigraphy were used. Planar imagery was negative at early and late stages but the complement by SPECT/CT made it possible due to fusion images to correlate the hyperfixation area of the tracer with the area of hyperplasia on the CT scans, increasing thus the sensitivity of the bone scintigraphy [9] [10] allowing the retained diagnosis of active unilateral mandibular hypercondylia.

\section{Conclusion}

This case confirms the fact that the SPECT/CT should be the examination of choice for the assessment of mandibular hypercondylia in adult; it improves both the sensitivity and the specificity of bone scintigraphy with a low irradiation rate and good value for money.

\section{Acknowledgements}

To the staff of the nuclear medicine service of Teaching Hospital Hassan 2 of Fez, Morocco.

\section{Ethics Approval and Consent}

Obtained by the ethics committee of the Teaching Hospital Hassan II and the Faculty of Medicine and Pharmacy of Fez.

\section{Consent for Publication}

Obtained from the patient.

\section{Availability of Data and Material}

Data sharing not applicable to this article as no datasets were generated or analysed during the current study.

\section{Funding}

No funding received. 


\section{Author's Contributions}

FF conceived of the study, participated in its design and wrote the manuscript. SM and NA participated in collecting personal data of the patient. NIA supervised the writing of this article. All the authors read and approved the final manuscript.

\section{Conflicts of Interest}

The authors declare that they have no competing interest regarding this article.

\section{References}

[1] Gordeff, A., Mercier, J.M. and Delaire, J. (1988) L'hypercondylie mandibulaire. Ses differents aspects cliniques et son traitement. Acta Stomatologica Belgica, 85, 259-276.

[2] Regaieg, B.F.M., Charfi, H., Sfar, R., Melki, S., et al. (2015) Hypercondylie unilatérale: Valeur de la scintigraphie osseuse et de ses différents protocoles d'acquisition. Médecine Nucléaire, 39, 32. https://doi.org/10.1016/j.mednuc.2015.03.094

[3] Choukry, S., Benouhoud, J., Zouine, S., Nadi, S. and Guensi, A. (2019) Apport de la scintigraphie osseuse dans les hypercondylies. Médecine Nucléaire, 43, 209. https://doi.org/10.1016/j.mednuc.2019.01.102

[4] Salagnac, J.M. (2002) Les hypercondylies mandibulaires: Éléments de diagnostic differential. Revue d Orthopédie Dento-Faciale, 36, 75-83. https://doi.org/10.1051/odf/2002002

[5] Nicot, R., Raoul, G. and Ferri, J. (2019) Hypercondylies. EMC Chirurgie orale et maxillo-faciale. Vol. 14.

[6] Wen, B., Shen, Y. and Wang, C.Y. (2014) Clinical Values of 99Tm-MDP SPECT Bone Scintigraphy in the Diagnosis of Unilateral Condylar Hyperplasia. Scientific World Journal, 2014, Article ID: 256256. https://doi.org/10.1155/2014/256256

[7] Pripatnanont, P., Vittayakittipong, P., Marmanee, U., et al. (2005) The Use of SPECT to Evaluate Growth Cessation of the Mandible in Unilateral Condylar Hyperplasia. International Journal of Oral and Maxillofacial Surgery, 34, 364-368. https://doi.org/10.1016/j.ijom.2004.11.002

[8] Delaire, J. (1977) Le traitement des hypercondylies mandibulaires. Plaidoyer pour la condylectomie. AOS, 117, 29-45.

[9] Hodder, S.C., Ress, J.I., Olivier, T.B., et al. (2000) SPECT Bone Scintigraphy in the Diagnosis and Management of Mandibular Condylar Hyperplasia. British Journal of Oral and Maxillofacial Surgery, 38, 87-93.

[10] Lopez, B.D.F. and Corral, S.C.M. (2016) Comparison of Planar Bone Scintigraphy and Single Photon Emission Computed Tomography for Diagnosis of Active Condylar Hyperplasia. Journal of Cranio-Maxillofacial Surgery, 44, 70-74. https://doi.org/10.1016/j.jcms.2015.10.026 